\title{
Labor force participation and secondary education of gender inequality index (GII) associated with healthy life expectancy (HLE) at birth
}

Jong In Kim ${ }^{1 *}$ and Gukbin Kim²

\begin{abstract}
Background: What is the factor that affects healthy life expectancy? Healthy life expectancy (HLE) at birth may be influenced by components of the gender inequality index (GII). Notably, this claim is not tested on the between components of the Gll, such as population at least secondary education (PLSE) with ages 25 and older, labor force participation rate (LFPR) with ages 15 and older, and the HLE in the world's countries. Thus, this study estimates the associations between the PLSE, LFPR of components of the GII and the HLE.

Methods: The data for the analysis of HLE in 148 countries were obtained from the World Health Organization. Information regarding the GII indicators for this study was obtained from the United Nations database. Associations between these factors and HLE were assessed using Pearson correlation coefficients and regression models.

Results: Although significant negative correlations were found between HLE and the LFPR, positive correlations were found between HLE and PLSE. Finally, the HLE predictors were used to form a model of the components of the GIl, with higher PLSE as secondary education and lower LFPR as labor force $\left(R^{2}=0.552, P<0.001\right)$.

Conclusions: Gender inequality of the attainment secondary education and labor force participation seems to have an important latent effect on healthy life expectancy at birth. Therefore, in populations with high HLE, the gender inequalities in HLE are smaller because of a combination of a larger secondary education advantage and a smaller labor force disadvantage in male-females.
\end{abstract}

Keywords: Gender Inequality Index, Healthy life expectancy, Secondary education, Labor force participation

\section{Background}

The healthy life expectancy (HLE) summarizes mortality and non-fatal outcomes in a single measure of average population health. The HLE increases more slowly than life expectancy [1]. The HLE is a related statistic that estimates the equivalent years that a person can expect to live in full health based on the current mortality rates and the prevalence distribution of health states in the population [2].

The HLE index was first used as a measure by the WHO in 2000 [3], combining information on mortality and morbidity [4]. However, the HLE - related quality of life, sometimes called health-adjusted life expectancy, is

\footnotetext{
*Correspondence: kji122@wku.ac.kr

'Division of Health and Welfare, Wonkwang University, Iksan-si, Republic of Korea

Full list of author information is available at the end of the article
}

a health expectancy indicator that expands measures of life expectancy to represent the average health in a population, in the terms of equivalent years of full health, taking into account the distribution of health states [5]. Thus, the HLE is defined as an estimate of the average number of years that a person can expect to live in full health, by taking into account years lived in less than full health due to disease and/or injury [6]. The resulting studies of the HLE have been conducted in some countries [1,3-5,7-10]. However, the studies for secondary education and labor force participation of components of the gender inequality index (GII) have a few examined on the effects associated with HLE [7-10]. The retrospective analysis of those factors that contribute to the HLE may help identify factors associated with the GII. Thus, the HLE has been used to compare full health between countries [1]. These comparisons can inform policy questions regarding equality 
of human rights that depend on components of the GII. We consider how the HLE correlates with components of GII.

In the course of the twentieth century, the overall mortality reduction was more beneficial for women and resulted in a substantial widening of the male and female longevity gap [7]. Until today, life expectancy of women exceeds that of men, although the size of the gender gap varies between populations [8]. However, the study showed that due to the combination of the higher prevalence of disability and lower mortality women spent substantially more years with disability than men $[7,9]$. Health expectancies, predominantly disability-free life expectancy, are available for many countries worldwide [10].

Thus, gender inequalities in HLE, can be split into two components of GII: (1) the inequality in secondary education and (2) in labor force participation. The current study is to better understand the secondary education and labor force participation of GII within the 148 countries by examining the contribution of women's HLE advantage or disadvantage. We expect that in populations with high HLE, the gender inequalities in HLE are smaller because of a combination of a larger secondary education advantage and a smaller labor force disadvantage in females.

To reduce gender inequalities, insight is needed into the underlying causes of the inequalities, as these may point at possible interventions, either at the societal level, to reduce them [7]. Though several biological hypotheses have been proposed, the dynamics of the gender differences in mortality suggest that its determinants cannot be purely biological, but are also dependent on modifiable psychosocial and lifestyle factors [10].

Although knowledge regarding the determinants of health is limited, full health is a multifactorial quantitative trait that is influenced by biological, environmental, and psychosocial factors [11]. Among all these elements, the components of the GII, as modifiable risk factors, have not been studied in relation to the HLE of full health. Briefly, although studies have shown that educational factors, such as educational inequalities [12-17], can predict morbidity in incidences of disease, but it is currently uncertain whether these associations are applicable to the HLE and percentage of population at least secondary education (PLSE) with ages 25 and older as empowerment of components of GII. Furthermore, the association between educational attainment status, at least secondary education in ages 25 and older, and the HLE of full health and empowerment has not been studied [12-19].

Meanwhile, although studies have shown that labour force factors, such as labor force participation [20-25], can predict morbidity, this study was designed to test whether these associations are applicable to the HLE and percentage of population labor force participation rate (LFPR) with ages 15 and older as labour market of GII. Furthermore, although there have been studies investigating the effect of child labor on the growth of children [26-29], the association between labor force participation with ages 15 and older and the HLE has not been studied. We are uncertain whether these labor associations are applicable to the HLE.

The HLE may be influenced by components of the GII. Notably, this claim is not tested on the between components of the GII such as PLSE, LFPR and HLE in the world's countries. Thus, this study estimates the associations between the PLSE, LFPR and HLE in 148 countries.

\section{Methods}

\section{The framework of HLE and components of GII}

The HLE index expands measures of life expectancy to represent the average health in a population in terms of equivalent years of full health [5]. However, the GII measures gender inequalities in three important aspects of human development [30]. In other words, GII measures reflecting inequality in achievements between women and men in three dimensions and five indicators: reproductive health (maternal mortality and adolescent fertility), empowerment (parliamentary representation and secondary education attainment) and the labor market (labor force participation) [30,31]. Thus, The GII reflects women's disadvantage in three dimensions for as many countries as data of reasonable quality allow. It ranges from 0 , which indicates that women and men fare equally, to 1 , which indicates that women fare as poorly as possible in all measured dimensions. The reproductive health dimension is measured by two indicators: maternal mortality ratio (MMR) and adolescent fertility rates (AFR). However, in this study excluded indicator of MMR and AFR because that the HLE is a measure of mortality and morbidity with another measure of mortality and morbidity; MMR is the same as correlating mortality with mortality and is not scientifically sound. The empowerment dimension is also measured by two indicators: the share of seats in national parliament (SNP) held by female and by educational attainment of secondary level and above percentage of population at least secondary education (PLSE) with ages 25 and older by gender. However, in this study is excluded indicator of SNP since the number of countries covered varies with suspensions or dissolutions of parliaments, there can be difficulties in obtaining information on by-election results and replacements due to death or resignation, and the use national parliamentary representation excludes participation at the local government level and elsewhere in community and public life [30]. The labor dimension is measured by labor force participation rate (LFPR) with ages 15 and older by gender. The GII is designed to reveal the extent to which national 
achievements in these aspects of human development are eroded by gender inequality, and to provide empirical foundations for policy analysis and advocacy efforts [30,31].

Therefore, on the assumption that the HLE may be influenced by components of the GII, the framework of this study depicts relationships between the HLE, as life expectancy to full health, and components of the GII reflecting the two dimensions: the PLSE as empowerment measures, and the LFPR as a labor measure (Figure 1).

\section{Estimation of HLE}

The equivalent lost healthy year fractions required for the HLE calculation are estimated as the all-cause years lost due to disability (YLD) rate per capita, adjusted for independent comorbidity, by age, sex and country. Sullivan's method uses the equivalent lost healthy year fraction at each age in the current population to divide the hypothetical years of life lived by a period life table cohort at different ages into years of equivalent full health and equivalent lost healthy years [6]. However, the first challenge is lack of reliable data on mortality and morbidity, especially from low-income countries. Other issues include lack of comparability of self-reported data from health interviews and the measurement of healthstate preferences for such self-reporting [6]. Thus, concerning the year, the HLE in this study reflects the [Male and Female (MF)], [Male (M)], and [Female (F)] for the year 2007 as a retrospective study.

\section{Hypothesis and setting model}

In order to examine the association between HLE disparities and the components of the GII, we need to develop a study model with each variable. This model was used to estimate HLE in terms of the components of the GII. The models depict the framework proposed herein of the components of the GII, according to the variables selected. The three models [HLE (MF), HLE (M) and HLE (F)] yielded the following results. The HLE predictors were used to form a combination model, from model [HLE (MF)] to model [HLE (F)] of the full health factors with PLSE as empowerment and LFPR as labor market factors. These variables are reflective of the components of the GII. Thus, these indirectly packing factors [PLSE (F) and LFPR (F)] to full health may differ for healthy life expectancy. Therefore, from this model, we derived a hypothesis stating that increases in the PLSE (F), and decreases in the LFPR (F) will lead to a corresponding increase in the HLE. Thus, associations between these factors and HLE of from this model were assessed using Pearson correlation coefficients and regression models.

\section{Data collection for the HLE and GII}

This study utilized the demographic databases of 148 countries for calculations. The data for the analysis of the HLE were obtained from the healthy life expectancy at birth conducted by World Health Organization (WHO) [32]. The countries and overseas island dependencies were selected according to the classification system applied by the United Nations. The 148 countries were selected in

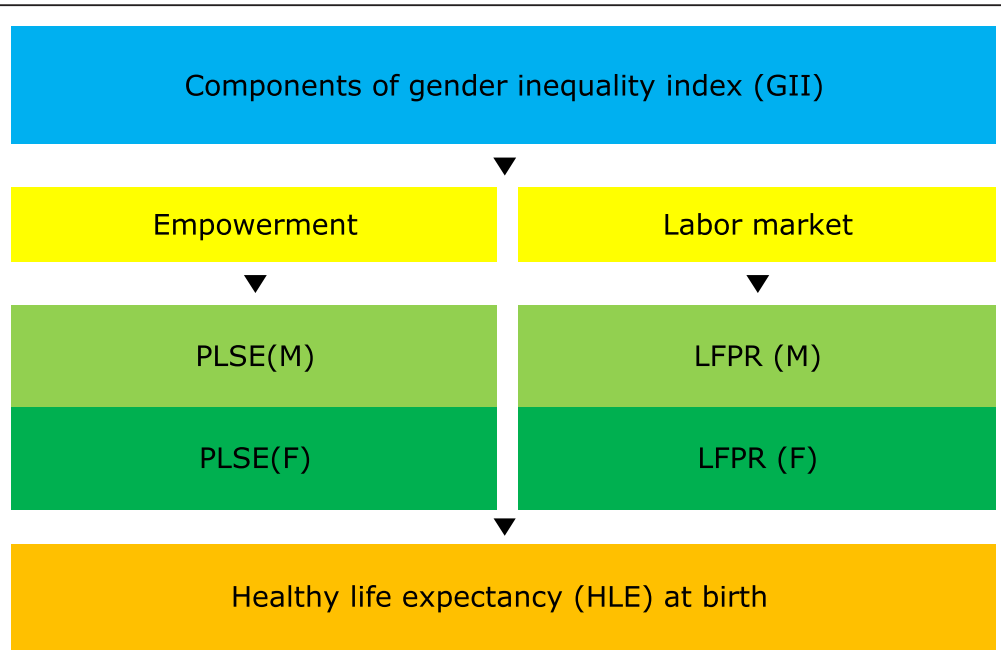

PLSE: Population with at least secondary education (\%, ages 25 and older)

LFPR: Labour force participation rate (\%, ages 15 and older)

M: Male F: Female

Figure 1 Description of theoretical framework. 
the more and less developed regions. The components of the GII for this study were obtained from a dataset in the United Nations database [33]. The following factors were used: (1) the PLSE (percentage, ages 25 and older) of GII, 2010; (2) the LFPR (percentage, ages 15 and older) of GII, 2011.

\section{The HLE, PLSE and LFPR disparities}

Table 1 presents the descriptive statistics for this range of HLE along with the components of the GII such as PLSE and LFPR indicators. Generally, the HLE (MF) related quality of life in 148 countries ranged from 35, to 76 , with a mean of 60.58 . The HLE (MF) disparity between the countries was 41 years. The HLE (M) - related quality of life ranged from 34 to 73 , with a mean of 59.11. However, the HLE (F) ranged from 36 to 78, with a mean of 62.09. The HLE (F) disparity between the countries was 42 years. Meanwhile, the PLSE (F) ranged from 0.9 to 100 , with a mean of 53.16. The PLSE (F) disparity between the countries was $99.1 \%$. Lastly, the LFPR (F) ranged from 13.1 to 88.2 , with a mean of 52.68. The LFPR (F) disparity between the countries was $75.1 \%$. Therefore, the descriptive statistics for this range of HLE indicators are presented the higher HLE (Female) than HLE (Male) in 148 countries. The HLE (Male) and HLE (Female) disparity between the countries was 2.98 years.

\section{Results}

\section{The prediction variables of HLE}

Table 2, Figure 2a-d and Figure 3a-d and Table 3 present the analysis of the PLSE and the LFPR factors related to the HLE in 148 countries.

In the interactions between education and labor force participation, the PLSE (M) was correlated with the LFPR (M) as components of the GII $(r=-0.557, \mathrm{P}=0.001$, $\mathrm{N}=148$ ). Although significant negative correlations were found between the PLSE (M) and the LFPR (M), non-correlations were found between the PLSE (F) and LFPR (F) in 148 countries.

Table 1 Descriptive statistics of variable

\begin{tabular}{llllll}
\hline Variable & $\mathbf{N}$ & Mean & StDev $^{\mathbf{a}}$ & Minimum & Maximum \\
\hline HLE (MF) & 148 & 60.58 & 9.98 & 35 & 76 \\
HLE (M) & 148 & 59.11 & 9.623 & 34 & 73 \\
HLE (F) & 148 & 62.09 & 10.49 & 36 & 78 \\
PLSE (M) & 148 & 58.62 & 27.8 & 3.2 & 100 \\
PLSE (F) & 148 & 53.16 & 30.67 & 0.9 & 100 \\
LFPR (M) & 148 & 74.78 & 8.052 & 45.1 & 95.2 \\
LFPR (F) & 148 & 52.68 & 16.24 & 13.1 & 88.2 \\
\hline
\end{tabular}

${ }^{\mathrm{a} S t a n d a r d}$ deviation.

HLE: Healthy life expectancy at birth.

PLSE: Population with at least secondary education (\% ages 25 and older).

LFPR: Labour force participation rate (\% ages 15 and older).

MF: Male and Female, M: Male, F: Female.
The HLE, including male and female, for all 148 countries was correlated with the PLSE and the LFPR as components of the GII. Although significant negative correlations were found between the HLE and the labor force participation of LFPR (M) and LFPR (F), positive correlations were found between the HLE and educational attainment at least secondary level of PLSE (F) and PLSE (M) in 148 countries (Table 2). Here we consider comparing relative ratios. These measures are analyzed on the log scale. A log scale was used for all explanatory variables (see Figures $2 \mathrm{a}-\mathrm{d}$ and $3 \mathrm{a}-\mathrm{d}$ ).

In order to investigate the direct relationships between the components of the GII such as the PLSE and the LFPR indicators and the HLE for all 148 countries, we conducted a multiple regression analysis. The regression analysis of the components of the GII found the strongest predictors among the three regression models (Table 3). The HLE (MF) predictors were used to form a model of the components of the GII, with lower LFPR (F) and higher PLSE $(F)$ in 148 countries $\left(R^{2}=0.532, P<0.001\right)$. Finally, the HLE (F) predictors were used to form a model of the components of the GII, with lower LFPR (F) and higher PLSE $(\mathrm{F})\left(\mathrm{R}^{2}=0.552, \mathrm{P}<0.001\right)$.

\section{Discussion}

Gender inequality remains a major barrier to human development. Females have made major strides since 1990, but they have not yet gained gender equity [30]. The disadvantages facing women and girls are a major source of inequality. All too often, females are discriminated against in education and labour market with negative repercussions for development of their capabilities and their freedom of choice [30]. Thus, we considered the associations between the HLE and the components of the GII such as the PLSE and the LFPR indicators to examine whether the lower HLE were disproportionately susceptible to full health.

The empowerment factors such as PLSE, which can contribute to healthy living, as indicators of women's HLE advantage. Increases in the PLSE, as components of the GII, led to an increase in HLE values, suggesting that they are significant contributory factors to the HLE in 148 countries. In the current study, the PLSE scores were the lowest in the less developed regions of Africa, whereas those scores were the highest in more developed regions, among any of the countries studied. This study have shown that educational attainment level, such as PLSE, as empowerment of components of GII, could predict the HLE, like that educational inequalities [12-17]. As such, the PLSE is likely to be a major contributing factor to higher HLE in 148 countries. Therefore, the PLSE (Female) that indirectly reflects the women's empowerment factors necessary for healthy living was to be significant factors of HLE (Female). This means that 
Table 2 Correlations Coefficient for HLE (MF), HLE (M) and HLE (F)

\begin{tabular}{|c|c|c|c|c|c|c|}
\hline \multirow[t]{2}{*}{ Variable } & \multicolumn{2}{|l|}{ HLE (MF) } & \multicolumn{2}{|l|}{ HLE (M) } & \multicolumn{2}{|l|}{ HLE (F) } \\
\hline & Coefficient & P-value & Coefficient & P-value & Coefficient & P-value \\
\hline PLSE (M) & 0.677 & 0.001 & 0.652 & 0.001 & 0.687 & 0.001 \\
\hline PLSE (F) & 0.699 & 0.001 & 0.672 & 0.001 & 0.710 & 0.001 \\
\hline LFPR (M) & -0.368 & 0.001 & -0.326 & 0.001 & -0.397 & 0.001 \\
\hline LFPR (F) & -0.270 & 0.001 & -0.271 & 0.001 & -0.276 & 0.001 \\
\hline
\end{tabular}

HLE: Healthy life expectancy at birth.

PLSE: Population with at least secondary education (\% ages 25 and older).

LFPR: Labour force participation rate (\% ages 15 and older).

MF: Male and Female, M: Male, F: Female.

if the HLE factors associated with women's empowerment improve by increasing female enrollment in secondary education, uplifting their social and political status with a greater share of female seats in the national parliament, then their healthy living will also improve. Thus, gender equity is also a crucial determinant of health inequalities at the national level, and is important for the surveillance of women's and men's health, as well as for future health policy initiatives [34]. This is particularly important because of the associations that exist between gender equality and empowerment among women [35]. Furthermore, women's right to health has been reiterated many times. However, there are social and cultural barriers in developing countries that hinder their empowerment [36,37]. On the other hand, the high correlations found in the current study between the HLE, and PLSE as components of the GII have bearing on government policies, since these variables are reflective of the government's investment in sociocultural education infrastructure for healthy living.
Change needs to happen on the political and cultural level if there is to be gender equality in more developed countries. Therefore, the HLE (Female) level seems to have an important latent effect on women's empowerment, improving in relation to female enrollment in secondary education and to their social status.

The labor market factor is an indicator of labor force participation, which can contribute to healthy living. Decreases in LFPR, as a component of the GII, led to an increase in the HLE values, suggesting that LFPR is a significant contributory factor to the HLE. In the current study, the LFPR in Eastern Europe were the lowest among all the 148 countries, whereas those of East Africa were the highest. As such, the LFPR is likely to be a major contributing factor to a high HLE. The decreases in LFPR (Female) led to an increase in the HLE, suggesting that LFPR (Female) is a significant factor of HLE (Female). The LFPR (F) as a component of the GII, which reflects the labor force participation level for those aged 15 and older,
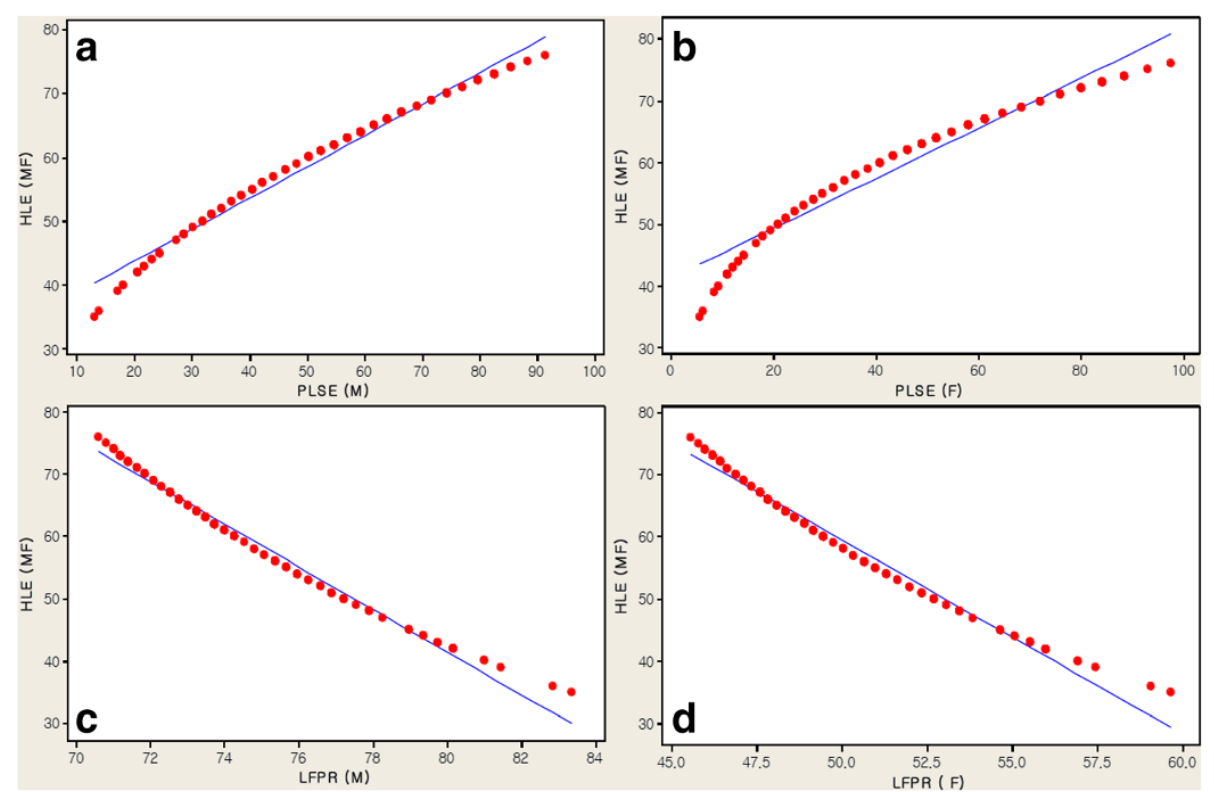

Figure 2 HLE (MF) associated with PLSE and LFPR. a. HLE (MF) associated with PLSE (M). b. HLE (MF) associated with PLSE (F). c. HLE (MF) associated with LFPR (M). d. HLE (MF) associated with LFPR (F). 

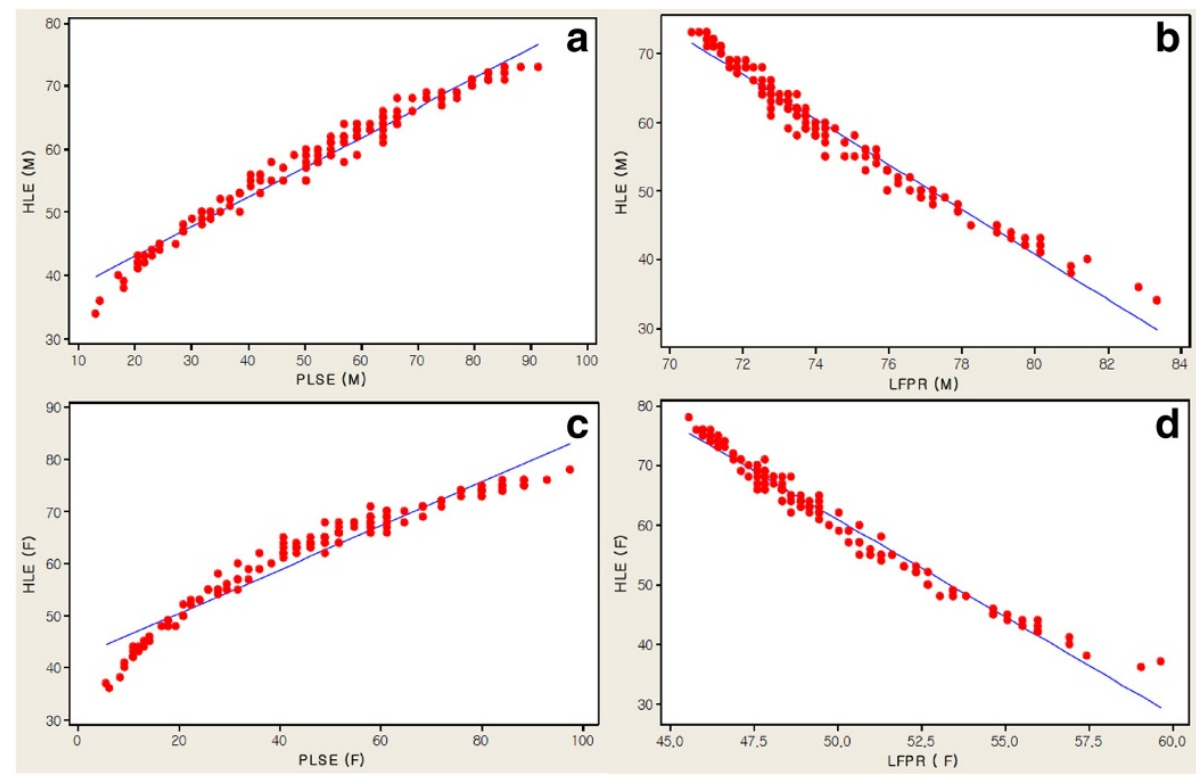

Figure 3 HLE (M and F) associated with PLSE and LFPR. a. HLE (M) associated with PLSE (M). b. HLE (M) associated with LFPR (M). c. HLE (F) associated with PLSE (F). d. HLE (F) associated with LFPR (F).

was to be significant factor of HLE in less developed regions. In the current study has shown that labour force level, such as LFPR labour market of components of GII, could predict the HLE, like that labor force participation [20-25]. For example, the labour force participation has a significant negative effect on younger males' health [38]. Furthermore, the higher the rate of labor force participation for those aged 15 and older, the less value of the HLE (Male-Female) will be, with the result that poor health increased the risk of disability pension, but was not related to early retirement [39]. A lack of physical activity could be a determinant of disability pension and unemployment $[39,40]$. Therefore, in this study, the lower LFPR (MaleFemale) is an important independent contributor to higher HLE (Male-Female) of healthy life.

In the HLE calculation of WHO, the limitation of this study is lack of comparability of self-reported data from

Table 3 Prediction variables for HLE (MF), HLE (M) and HLE (F)

\begin{tabular}{llllll}
\hline Predictions variable & Coefficient & T-value & P-value & $\mathbf{R}^{\mathbf{2}}$ \\
\hline HLE (MF) & PLSE (F) & 0.221 & 11.94 & 0.001 & 0.532 \\
& LFPR (F) & -0.131 & -3.71 & 0.001 & \\
HLE (M) & PLSE (F) & 0.205 & 11.07 & 0.001 & 0.498 \\
& LFPR (F) & -0.128 & -3.65 & 0.001 & \\
HLE (F) & PLSE (F) & 0.237 & 12.38 & 0.001 & 0.552 \\
& LFPR (F) & -0.141 & -3.88 & 0.001 &
\end{tabular}

HLE: Healthy life expectancy at birth.

PLSE: Population with at least secondary education (\% ages 25 and older). LFPR: Labour force participation rate (\% ages 15 and older).

MF: Male and Female, M: Male, F: Female. health interviews and the measurement of health-state preferences for such self-reporting [6]. In some countries, estimates of HLE are subject to the uncertainty, especially for countries with weak statistical and health information systems where the quality of underlying empirical data is limited [32]. The GII of this study is excluded indicator of share of seats in national parliament (SNP) in empowerment and reproductive health (MMR and AFR). However, it is important to clarify that the direct relationships between the components of the GII such as the PLSE and the LFPR indicators and the HLE.

Hence, the hypothesis that if the countries for the proposed three models [HLE (Male-Female), HLE (Male) and HLE (Female)] were to have lower LFPR (Female) and higher PLSE (Female), the associations between components of the GII and HLE could predict a certain impact on the increase of the HLE. In other words, HLE is a state of gender equality in labor force participation and secondary education. Furthermore, the HLE is based on the healthy longevity or survival probability of becoming a healthy centenarian $[41,42]$.

\section{Conclusion}

Gender inequality of the attainment secondary education and labor force participation seems to have an important latent effect on healthy life expectancy at birth. Therefore, in populations with high HLE, the gender inequalities in HLE are smaller because of a combination of a larger secondary education advantage and a smaller labor force disadvantage in females. 


\section{Competing interests}

The authors declare that they have no competing interests.

\section{Authors' contribution}

JIK conceived the study, data analysis, statistical analysis and drafted the manuscript. JIK made a substantial contribution to the analysis and interpretation of the data and final writing of the paper. GBK contributed to the collection and arrangement of the data. Both authors read and approved the final manuscript.

\section{Acknowledgements}

We appreciate the reviewers for comments that have improved the manuscript.

This paper was sponsored by Wonkwang University in 2014.

\section{Author details}

${ }^{1}$ Division of Health and Welfare, Wonkwang University, Iksan-si, Republic of Korea. ${ }^{2}$ Management with International Business (BSc), Royal Holloway, University of London, London, UK.

Received: 4 March 2014 Accepted: 19 October 2014

Published online: 18 November 2014

\section{References}

1. Salomon JA, Wang H, Freeman MK, Vos T, Flaxman AD, Lopez AD, Murray CJ: Healthy life expectancy for 187 countries, 1990-2010: a systematic analysis for the Global Burden Disease Study 2010. Lancet 2012, 380(9859):2144-2162.

2. World Health Organization (WHO): Life expectancy. In Health topics; 2013. http://www.who.int/topics/life_expectancy/en.

3. World Health Organization (WHO): World Health Report 2000- Health Systems: improving Performance. Geneva: WHO; 2000.

4. Mathers CD, Sadana R, Salomon JA, Murray CJ, Lopez AD: Healthy life expectancy in 191 countries, 1999. Lancet 2001, 357:1685-1691.

5. Murray CJL, Salomon JA, Mathers CD: A critical examination of summary measures of population health. Bull World Health Organ 2000, 78:981-994. Organization.

6. World Health Organization (WHO): Healthy life expectancy at birth. 2013 http://apps.who.int/gho/indicatorregistry/App_Main/view_indicator.aspx? $\mathrm{iid}=66$.

7. Nusselder WJ, Looman CW, Van Oyen H, Robine JM, Jagger C: Gender differences in health of EU10 and EU15 populations: the double burden of EU10 men. Eur J Ageing 2010, 7(4):219-227.

8. Jagger C, Gillies C, Moscone F, Cambois E, Van Oyen H, Nusselder W, Robine JM EHLEIS team: Inequalities in healthy life years in the 25 countries of the European Union in 2005: a cross-national meta-regression analysis. Lancet 2008, 372(9656):2124-2131.

9. Case A, Paxson C: Sex differences in morbidity and mortality. Demography 2005, 42:189-214

10. Van Oyen H, Nusselder W, Jagger C, Kolip P, Cambois E, Robine JM: Gender differences in healthy life years within the EU: an exploration of the "health-survival" paradox. Int J Public Health 2013, 58(1):143-155.

11. Candore G, Balistreri CR, Listì F, Grimaldi MP, Vasto S, Colonna-Romano G, Franceschi C, Lio D, Caselli G, Caruso C: Immunogenetics, gender, and longevity. Ann N Y Acad Sci 2006, 1089:516-537.

12. Menvielle G, Rey G, Jougla E, Luce D: Diverging trends in educational inequalities in cancer mortality between men and women in the 2000s in France. BMC Public Health 2013, 13:823.

13. Jackson CL, Szklo M, Yeh HC, Wang NY, Dray-Spira R, Thorpe R, Brancati FL: Black-white disparities in overweight and obesity trends by educational attainment in the United States, 1997-2008. J Obes 2013, 2013:140743.

14. Jwa SC, Fujiwara T, Hata A, Arata N, Sago H, Ohya Y: BMI mediates the association between low educational level and higher blood pressure during pregnancy in Japan. BMC Public Health 2013, 13:389.

15. Landman GW, Kleefstra N, van Hateren KJ, Gans RO, Bilo HJ, Groenier KH: Educational disparities in mortality among patients with type 2 diabetes in The Netherlands (ZODIAC-23). Neth J Med 2013, 71(2):76-80.

16. Östgren CJ, Sundström J, Svennblad B, Lohm L, Nilsson PM, Johansson G: Associations of $\mathrm{HbA} 1 \mathrm{C}$ and educational level with risk of cardiovascular events in 32,871 drug-treated patients with Type 2 diabetes: a cohort study in primary care. Diabet Med 2013, 30(5):e170-e177.
17. Kulik MC, Menvielle G, Eikemo TA, Bopp M, Jasilionis D, Kulhánová I, Leinsalu M, Martikainen P, Östergren O, Mackenbach JP: EURO-GBD-SE Consortium: Educational Inequalities in Three Smoking-Related Causes of Death in 18 European Populations. Nicotine Tob Res 2014 16(5):507-518.

18. Søndergaard G, Mortensen LH, Nybo Andersen AM, Andersen PK, Dalton SO, Madsen M, Osler M: Does shared family background influence the impact of educational differences on early mortality? Am J Epidemiol 2012, 176(8):675-683.

19. Moe JO, Steingrímsdóttir ÓA, Strand BH, Grøholt EK, Næss $\varnothing$ : Trends in educational inequalities in old age mortality in Norway 1961-2009: a prospective register based population study. BMC Public Health 2012, 12:911.

20. Schofield DJ, Callander EJ, Shrestha RN, Passey ME, Percival R, Kelly SJ: Multiple chronic health conditions and their link with labour force participation and economic status. PLOS One 2013, 8(11):e79108.

21. Churcher $\mathrm{L}$, Chan $\mathrm{CH}$, Badley EM: Chronic back problems and labor force participation in a national population survey: impact of comorbid arthritis. BMC Public Health 2013, 13:326.

22. Mushtaq A, Mohsin A, Zaman K: Effects of health on changing labor force participation in Pakistan. Springerplus 2013, 2:610.

23. Carter KN, Gunasekara Fl, Blakely T, Richardson K: Health shocks adversely impact participation in the labour force in a working age population: a longitudinal analysis. Aust N Z J Public Health 2013, 37(3):257-263.

24. Webber DA, Bjelland MJ: The impact of work-limiting disability on labor force participation. Health Econ 2013, doi:10.1002/hec.3020.

25. Kassam A, Patten SB: Major depression, fibromyalgia and labour force participation: a population-based cross-sectional study. BMC Musculoskelet Disord 2006, 7:4.

26. Hawamdeh $H$, Spencer $N$ : Effect of work related variables on growth among working boys in Jordan. J Epidemiol Community Health 2003, 57(2):154-158.

27. Mishra D, Arora P: Domestic child labor. Indian Pediatr 2007 44(4):291-292.

28. Ambadekar NN, Wahab SN, Zodpey SP, Khandait DW: Effect of child labour on growth of children. Public Health 1999, 113(Suppl 6):303-306.

29. Duyar I, Ozener B: Growth and nutritional status of male adolescent laborers in Ankara. Turkey Am J Phys Anthropol 2005, 128(Suppl 3):693-698.

30. United Nations (UN) a: Gender Inequality Index. Human Development Report. http://hdr.undp.org/en/statistics/gii/, Accessed on August 15, 2013: Comments and limitations. http://mdgs.un.org/unsd/mdg/Metadata.aspx? Indicatorld=0\&Seriesld=557. Accessed on July 28, 2014.

31. Rahi M: Human development report 2010: changes in parameters and perspectives. Indian J Public Health 2011, 55(Suppl 4):272-275.

32. World Health Organization (WHO): Data, Healthy life expectancy at birth. http://apps.who.int/gho/data/node.main.3?lang=en. Accessed on August 15, 2013: Mortality and burden of disease. Healthy life expectancy (HALE) at birth (years) (2007). http://www.who.int/gho/publications/world_health statistics/EN_WHS10_Part2.pdf. Accessed on August 22, 2014.

33. United Nations (UN) b: Gender Inequality Index. In UN data, Dataset; 2013. http://data.un.org/DocumentData.aspx?q=Gender+Inequality+Index\&id=332.

34. Fernández-Sáez J, Ruiz-Cantero MT, Guijarro-Garví M, Carrasco-Portiño M, Roca-Pérez V, Chilet-Rosell E, Álvarez-Dardet C: Looking twice at the gender equity index for public health impact. BMC Public Health 2013, 13:659.

35. Kabeer K: Gender equality and women's empowerment: a critical analysis of the third millennium development goal 1. Gend Dev 2005, 13(1):13-24

36. Qureshi N, Shaikh BT: Women's empowerment and health: the role of institutions of power in Pakistan. East Mediterr Health J 2007 13(Suppl 6):1459-1465.

37. Dargan R: Gender equality and women empowerment. Roshni 1996, 19-20.

38. Cai L, Kalb G: Health status and labour force participation: evidence from Australia. Health Econ 2006, 15(3):241-261.

39. Robroek SJW, Schuring M, Croezen S, Stattin M, Burdorf A: Poor health, unhealthy behaviors, and unfavorable work characteristics influence pathways of exit from paid employment among older workers in Europe: a four year follow-up study. Scand J Work Environ Health 2013, 39(2):125-133.

40. Van den Berg T, Schuring M, Avendano M, Mackenbach J, Burdorf A: The impact of ill health on exit from paid employment in Europe among older workers. Occup Environ Med 2010, 67(12):845-852. 
41. Kim Jl: Social factors associated with centenarian rate (CR) in $32 \mathrm{OECD}$ countries. BMC Int Health Hum Rights 2013, 13:16.

42. Kim Jl, Kim G: Factors affecting the survival probability of becoming a centenarian for those aged 70 , based on the human mortality database: income, health expenditure, telephone, and sanitation. BMC Geriatr 2014, 14:113.

doi:10.1186/s12939-014-0106-2

Cite this article as: Kim and Kim: Labor force participation and secondary education of gender inequality index (GII) associated with healthy life expectancy (HLE) at birth. International Journal for Equity in Health 2014 13:106

\section{Submit your next manuscript to BioMed Central and take full advantage of:}

- Convenient online submission

- Thorough peer review

- No space constraints or color figure charges

- Immediate publication on acceptance

- Inclusion in PubMed, CAS, Scopus and Google Scholar

- Research which is freely available for redistribution 